\title{
A cidade vista pelos habitantes do campo de Araponga/MG: uma análise das representações sociais por meio do software Alceste
}

\author{
The city seen by the inhabitants of the countryside of Araponga/MG: na analysis \\ of social representations through Alceste software
}

\author{
Nayhara Freitas Martins Gomes ${ }^{1}$ (D), Ana Louise Carvalho Fiúza² ${ }^{\text {DD }}$, Neide Maria Almeida Pinto ${ }^{3}$ (D) \\ ${ }^{1}$ Instituto de Geociências, Programa de Pós-graduação em Geografia, Universidade Federal de Minas Gerais (UFMG), Belo \\ Horizonte (MG), Brasil. E-mail: nayhara_martins@yahoo.com.br \\ ${ }^{2}$ Departamento de Economia Rural, Programa de Pós-graduação em Economia Doméstica, Universidade Federal de Viçosa \\ (UFV), Viçosa (MG), Brasil. E-mail: louisefiuza@ufv.br \\ ${ }^{3}$ Departamento de Economia Doméstica, Programa de Pós-graduação em Economia Doméstica, Universidade Federal de \\ Viçosa (UFV), Viçosa (MG), Brasil. E-mail: nalmeida@ufv.br
}

Como citar: Gomes, N. F. M., Fiúza, A. L. C., \& Pinto, N. M. A. (2020). A cidade vista pelos habitantes do campo de Araponga/MG: uma análise das representações sociais por meio do software Alceste. Revista de Economia e Sociologia Rural, 58(2), e176516. https://doi.org/10.1590/1806-9479.2020.176516

\begin{abstract}
Resumo: A relação entre campo e cidade vem se modificando de forma acentuada, especialmente, a partir das últimas duas décadas do século XX. O presente artigo fez uma análise da forma como a população rural de um pequeno município de economia cafeeira, localizado na Zona da Mata mineira, manifesta, por meio das suas representações de "campo" e "cidade", a percepção de aproximações e diferenças quanto ao modo de vida rural e urbano na atualidade. O estudo teve um caráter crosssectional, tendo sido realizado por intermédio de um questionário semiestruturado, com uma amostra representativa da população composta de 94 rurais. Na aplicação do questionário, utilizou-se da técnica de mesclagem de perguntas, que estimulavam respostas rápidas e espontâneas, com outras de cunho mais reflexivo. Com base nas respostas obtidas, o corpus para análise quantitativa de dados textuais foi preparado no software Alceste. Os resultados referentes às representações espontâneas e reflexivas manifestadas pelos rurais acerca da "cidade" e do "campo" revelaram uma visão social de mundo marcada pela perspectiva do pertencimento à dinâmica citadina, combinada com as marcas de ruralidade constitutivas de sua identidade.
\end{abstract}

Palavras-chave: representação social, rurais, relação campo/cidade, Alceste.

Abstract: The relationship between the countryside and the city has been changing markedly, especially since the last two decades of the 20th century. The present article aimed to analyze how the rural population of a small coffee - growing municipality located in the Zona da Mata, Minas Gerais, manifested through its representations of "countryside" and "city" the approximations and differences about the way of life in both spaces. This study had a cross-sectional character and was carried out through the application of a semi-structured questionnaire, with a representative sample of the population, composed by 94 rural households. In the application of the questionnaire, it was used the technique of mixing questions that stimulated quick and spontaneous responses, with others of a more reflective nature. Based on the answers obtained, the corpus was prepared for the quantitative analysis of textual data, in Alceste software. The results concerning the spontaneous and reflexive representations that the rural ones expressed about the "city" and the "countryside" revealed a social vision of the world marked by the perspective of belonging to the city dynamics, combined with the rurality marks constituting his identity.

Keywords: social representation, rurals, countryside, city, Alceste. 


\section{INTRODUÇÃO}

A aproximação das relações entre o campo e a cidade pode ser observada por meio de vários fenômenos hodiernamente corriqueiros, tais como: o crescimento das ORNAs (Ocupações Rurais Não Agrícolas), com a ampliação à pluriatividade nas famílias de agricultores; a constância e a rapidez dos deslocamentos entre o campo e a cidade; a ampliação do acesso por parte dos rurais a serviços públicos de educação e saúde e a benefícios sociais; o crescimento do consumo de bens materiais como carro, moto, tecnologias da informação e comunicação (celular, telefone rural, internet e televisão) e eletrodomésticos. Todas essas mudanças acarretaram a incorporação de novos valores, hábitos e práticas pelos rurais, alterando os seus modos de vida, conforme sinalizaram em seus estudos Wanderley (2009), Carneiro (2012) e Hespanhol (2013).

O presente artigo veicula uma análise das representações sociais manifestadas pelos habitantes do campo do pequeno município de Araponga, em Minas Gerais, diante da realidade experimentada em relação à cidade, por meio de evocações espontâneas e reflexivas. Nas primeiras respostas, os 94 residentes rurais (homens e mulheres de diferentes gerações) tinham pouco tempo para pensar, tendo a recomendação de responder de forma imediata às perguntas que the eram feitas. Já nas respostas reflexivas, os entrevistados tinham tempo para responder. Os dados obtidos foram analisados por meio do software Alceste, com complemento de uma análise de conteúdo. A interpretação das representações sociais construídas pelos residentes do campo acerca da cidade permite realçar a forma como esses espaços se configuram no seu modo de vida e no seu cotidiano, expressando suas necessidades sentidas, bem como as motivações que orientam suas relações sociais e territoriais.

Para a análise, perguntou-se aos habitantes do campo - não exclusivamente agricultores - quais seriam as vantagens e as desvantagens em relação ao campo e à cidade, tal como Rambaud (1973) o fizera em sua pesquisa na França. Portanto, seguiu-se o mesmo procedimento adotado por esse autor: além da opinião espontânea e imediata dos rurais acerca das vantagens e das desvantagens relacionadas à cidade, solicitou-se aos respondentes um julgamento reflexivo sobre questões referentes à vida na cidade. Era proposto aos respondentes que manifestassem o seu nível de concordância diante das assertivas apresentadas.

Nas outras cinco seções que compõem este artigo, apresenta-se, incialmente, a concepção teórica de representação social, particularmente as abordagens de autores que trataram especificamente das questões relativas ao campo e à cidade. Em seguida, descrevem-se os percursos metodológicos relacionados ao uso do software Alceste, utilizado para a análise das representações dos rurais acerca da sua imagem do campo e da cidade. Depois, abordam-se as características atribuídas a ambos os espaços, assim como a compreensão que os rurais possuem acerca de características, diretrizes e valores norteadores da vida nesses espaços. Por fim, apresentam-se as principais conclusões.

\section{A REPRESENTAÇÃO SOCIAL DOS RURAIS DE CAMPO E DE CIDADE}

Para realizar a análise das representações dos rurais acerca do campo e da cidade, convém, primeiramente, apresentar a concepção teórica mobilizada para a realização de tal interpretação analítica. Segundo Sêga (2000), a representação social pode ser definida como uma forma de interpretar o cotidiano e pensar nele a partir das referências de vida que orientam as ações em diferentes situações e eventos da vida social. A representação social pode ser tomada como um conhecimento prático, uma linguagem coletiva comungada socialmente, estabelecendo, assim, uma conexão entre o mundo coletivo e as coisas. Segundo Candau (2011), a representação social organiza, classifica e categoriza os pensamentos, promovendo uma ancoragem cultural para absorção e interpretação do novo. Contudo, as representações coletivas não apontam para processos marcados pela consonância de ideias e não são livres de contradições.

Tais contradições valorativas acerca das representações de campo e cidade foram interpretadas por Williams (2011) mediante o estudo da literatura inglesa pós-revolução industrial. $O$ autor identificou a representação do campo tanto como um espaço vinculado à paz, à inocência e à simplicidade, como também um lugar de atraso, ignorância e 
limitação, contraposto à cidade, representada como um centro de realizações, de saber e de comunicações. No entanto, as representações sociais, embora não sejam unívocas, conseguem, segundo Moscovici (2010, p. 34-36), incutir um sentido ao comportamento, integrá-lo em uma rede de relações que está vinculada ao seu objeto, fornecendo, ao mesmo tempo, as noções e os fundos de observação que tornam essas relações estáveis e eficazes. Com efeito, as representações sociais situam as pessoas e os objetos em determinado lugar, ligando-os a certos grupos e estruturas. Para Serge Moscovici, o fato de o não familiar alarmar as impele a tornar explícitos os pressupostos implícitos que são básicos do consenso (Moscovici, 2010, p. 56).

As representações sociais constituem formas de conhecimentos socialmente elaborados, produzidas por grupos de indivíduos para se comunicarem e entenderem tudo aquilo que não Ihes é familiar. Assim, as representações sociais nada mais são que afirmações e explicações originadas no decurso do cotidiano e das comunicações interindividuais. Para Jodelet (2001, p. 21), devem ser reconhecidas enquanto sistemas de interpretação que regem relação com o mundo, orientando e organizando as condutas e as comunicações sociais. Entretanto, as representações sociais intervêm em processos variados como a difusão e assimilação de conhecimentos, o desenvolvimento individual e coletivo, a definição das identidades pessoais e sociais, a expressão dos grupos e as transformações sociais. Para a autora, as representações sociais são abordadas como produto e processo de uma atividade de apropriação da realidade exterior ao pensamento e de elaboração psicológica e social dessa realidade. De fato, representar corresponde a um ato de pensamento pelo qual um sujeito se reporta a um objeto. Dessa forma, as representações sociais são sempre as representações de alguma coisa e de alguém, em que as características do sujeito e do objeto se manifestam por meio da subjetividade do sujeito, ou seja, referem-se a uma relação de simbolização e interpretação, resultado da construção e da expressão dos sujeitos.

Nesse quadro, as representações sociais são fenômenos complexos que orientam a ação na vida social e abrangem diversos elementos (informativos, cognitivos, ideológicos, normativos, valorativos, opinativos e imaginários). Contudo, são organizados sempre sob a aparência de um saber que explica a realidade. Em suma, são formas de conhecimento socialmente elaboradas e compartilhadas, que contribuem para a construção de uma realidade comum a um conjunto social. Também designadas de "saber de senso comum" ou "saber ingênuo" ou "natural", distinguem-se do conhecimento científico, assumindo demasiada importância na vida social e na elucidação de fatos, o que possibilita a compreensão das interações sociais. Segundo Pereira \& Almeida (2015, p. 129), as representações sociais constituem, portanto, uma abordagem teórica e metodológica acerca do saber popular e do senso comum que coletivamente são elaborados e reproduzidos a fim de construir e interpretar determinada realidade.

Considerando as manifestações dos rurais acerca do campo e da cidade, o sociólogo Rambaud (1973) enfatizou que as representações sociais expressam a compreensão em relação aos espaços urbanos e rurais, evidenciando um julgamento consciente das vantagens e das desvantagens de cada um. Para Pereira (2004), essas imagens do campo e da cidade norteariam as relações que a sociedade rural estabelece com a cidade e consigo mesma, revelando os diferentes significados presentes no julgamento dos sujeitos. As representações sociais se constituem, enfim, em formas de conhecimento socialmente elaboradas e partilhadas, pressupondo um modo de legitimação social acerca dos fenômenos e acontecimentos que rodeiam os indivíduos. Brandão et al. (2014) advogam que, para os rurais, o campo, enquanto uma representação do seu espaço de vida, expressaria os significados simbólicos associados àquilo que habita o universo do sagrado, do imutável, traduzindo e revelando as tradições e os valores que se voltam para proteger a vida cotidiana das ameaças de desconfiguração do seu ambiente físico e social. Nesse sentido, a representação social tem com o seu objeto uma relação simbólica: ela pode substituí-lo, tornando-o presente quando ele está ausente. Essa relação pode também ser interpretativa, ou seja, conferindo ao objeto significados e sentidos (Jodelet, 2001). 


\section{PROCEDIMENTOS METODOLÓGICOS}

A fim de analisar as representações sociais do campo e da cidade manifestadas pela população rural do pequeno município de Araponga/MG, realizaram-se entrevistas semiestruturadas com perguntas que levavam o entrevistado a ponderar, de forma reflexiva, espontânea e rápida, as vantagens e as desvantagens relativas à vida no campo e na cidade. Adotou-se, na verdade, o mesmo procedimento realizado por Rambaud (1973) em sua pesquisa com os camponeses franceses no pós-Segunda Guerra Mundial. Nessa pesquisa, o autor buscou, além da opinião espontânea dos rurais sobre temas relacionados ao campo e à cidade, explorar também o julgamento reflexivo dos entrevistados sobre situações, normas e valores relativos à vida no campo e na cidade, dando-lhes tempo para justificar a sua concordância diante das diferentes assertivas apresentadas.

O município de Araponga foi escolhido em virtude de ter uma população inferior a 20 mil habitantes e ter uma economia agrícola, tal como acontece com mais de $80 \%$ dos municípios brasileiros (Veiga, 2004, p. 80). Além do mais, a seleção dessa localidade ocorreu em função da estreita relação de uma das pesquisadoras com a população rural desse município, por residir no campo e por ter desenvolvido pesquisa anterior ao longo da graduação. O espaço rural do município de Araponga, universo empírico e locus da pesquisa, apresentava em 2010 uma população de 8.152 habitantes: 3.041 vivendo na cidade e 5.011 no campo, respectivamente, 37,3\% e 62,7\% da população (Instituto Brasileiro de Geografia e Estatística, 2010). O município, localizado na Zona da Mata mineira e pertencente à Microrregião de Viçosa (Figura 1), possui dimensão territorial de 303,8 $\mathrm{km}^{2}$ e densidade demográfica de 26,8 hab/km. A economia de Araponga é típica de muitos municípios brasileiros, voltada para a prestação de serviços e atividades ligadas à agropecuária, sobretudo produção do café, cultivo predominante na região e principal fonte de renda dos residentes no campo. A pecuária e o turismo rural desenvolvido nas propriedades em torno do Parque Estadual da Serra do Brigadeiro são também atividades importantes do campo em questão (Miranda et al., 2016).

A estrutura agrária do município é composta de $85 \%$ de propriedades com menos de 50 hectares, correspondendo a 544 estabelecimentos, que detêm 37\% da área. Nessas propriedades predomina a agricultura de base familiar. Nos períodos da colheita do café, contudo, são contratados trabalhadores assalariados temporários. Já as propriedades com mais de 50 ha representam 15\% dos estabelecimentos e ocupam 63\% da área. Portanto, o campo de Araponga é ocupado, em sua maioria, por pequenos agricultores e apresenta uma estrutura agrária que se caracteriza por uma elevada fragmentação da propriedade rural, cuja viabilidade depende da tenacidade dos agricultores e da adoção de estratégias e formas de resistência cotidianas.

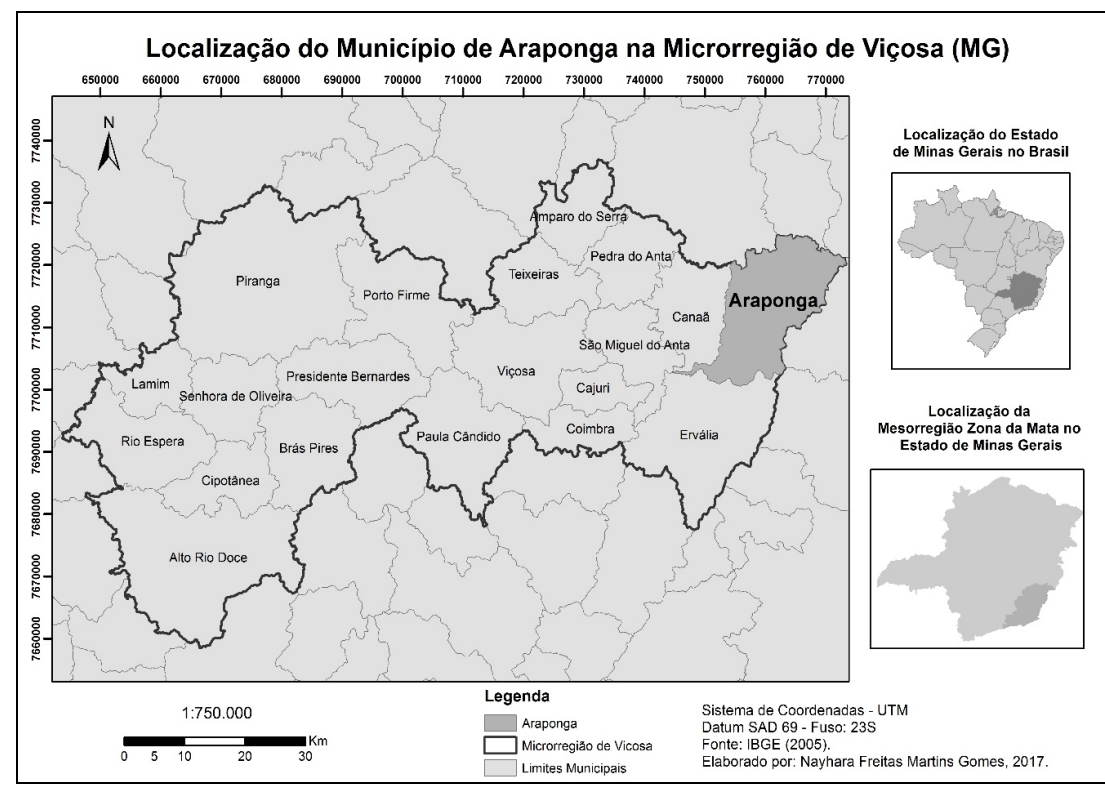

Figura 1 - Mapa da Microrregião de Viçosa (MG), com ênfase no pequeno município de Araponga. Fonte: Instituto Brasileiro de Geografia e Estatística (2010). 
Adotou-se neste estudo uma amostra probabilística e representativa da população, cujos indivíduos foram escolhidos por um processo em que todos tinham a mesma probabilidade de fazer parte da amostra. Assim, a amostra representativa permitiu que os resultados fossem confiáveis para avaliar as características da população. Em uma primeira etapa, para o cálculo da amostra, identificaram-se as unidades domiciliares rurais por meio de consulta aos dados cadastrais fornecidos pelas Unidades Básicas de Saúde (UBS) da Secretaria de Saúde de Araponga. O tamanho amostral foi definido segundo a fórmula da proporção finita de Bolfarine \& Bussab (2005, p. 28), assumindo-se erro de estimativa de $10 \%$ e grau de confiança de $95 \%$. Assim, a amostra foi composta de 94 indivíduos. Para a obtenção dos dados primários mediante entrevista semiestruturada, tomou-se como unidade de análise o indivíduo, segmentado em faixas etárias e sexo. As questões abertas foram sistematizadas e submetidas a análises estatísticas no software Alceste (Análise Lexical Contextual de um Conjunto de Segmento de Texto).

O Alceste é um software para análise de textos desenvolvido por Max Reinert (1986) na França. Esse programa, além de permitir uma análise lexical quantitativa que considera a palavra como unidade, também oferece a sua contextualização. Foi desenvolvido em contato com as necessidades e os problemas de pesquisadores, não somente utilizado no campo das ciências sociais aplicadas, mas em diferentes domínios que trabalhem com materiais discursivos como questionários e entrevistas. Além desse alcance, o Alceste é usado para analisar diferentes textos, não só elaborados a partir dos discursos de envolvidos em uma pesquisa, mas também aplicados à exploração de todos os tipos de texto como narrações literárias, informativos jornalísticos, livros, diálogos e ensaios. Desse modo, a utilização do Alceste e a análise das representações sociais possibilitam uma interpretação de um volume considerável de dados textuais, bem como a triangulação de dados qualitativos e quantitativos (Araújo et al., 2006, p. 92).

Segundo Alba (2004), o Alceste não é apenas um método de análise de dados textuais que ajuda explorar a estrutura e a organização do discurso. A originalidade do software está no seu princípio teórico por permitir a localização dos mundos lexicais que compõem o discurso por meio da análise de associações das principais palavras coocorrentes nas sentenças. Essas sucessões de palavras repetitivas associadas nos vários fragmentos do texto ajudam a descobrir laços temáticos ou associações de difícil acesso por intermédio de uma análise categórica tradicional (Reinert, 1993, p. 9). Existem razões metodológicas e teóricas para usar esse programa nos estudos acerca das representações sociais para fins de uma análise exploratória de um texto, com vistas a descobrir significados, sem imposição de categorias estabelecidas pelo analista. Não obstante, o Alceste gera uma variedade de resultados que ajudam a realizar uma interpretação completa dos dados. No âmbito deste trabalho, o software permite captar a representação social dos habitantes do campo em relação à cidade mediante o discurso sobre a experiência de vida citadina e seus aspectos positivos ou negativos.

Os envolvidos na pesquisa foram, portanto, questionados sobre os aspectos positivos e negativos relativos à sua percepção da cidade. Ademais, solicitou-se aos entrevistados uma postura reflexiva diante de determinados temas, acerca dos quais deveriam expressar o seu nível de concordância tomando como referência de mensuração uma escala de Likert, com valores gradativos de 1 a 5 ("1" significa "discordo totalmente", e 5, "concordo totalmente"). A adoção dessas evocações espontâneas e reflexivas foi similar ao que Rambaud realizou na França, no início dos anos 1970. As respostas abertas foram transcritas, e, posteriormente, cinco corpora foram estruturados. A escolha de questões considerou a possibilidade de uma análise das representações sociais acerca das vantagens e desvantagens do campo e da cidade, bem como da avaliação das condições da vida rural no passado e no presente. Para a obtenção dessa avaliação, solicitou-se aos residentes rurais de Araponga uma comparação entre a vida no campo naquele momento da entrevista e os tempos passados.

O programa Alceste constitui um método de estatística textual que identifica a organização tópica do discurso. Para iniciar as análises no programa, o corpus estruturado foi convertido a um arquivo de documento Word for Windows 2013, salvo no tipo texto "txt" e transportado para o Alceste iniciar as análises. Ressalta-se que o corpus de análise é lido pelo programa por meio das cinco Unidades de Contexto Iniciais (UCls) correspondentes a cada indivíduo envolvido na pesquisa com suas respectivas respostas. Durante a análise dos dados, o software realiza quatro etapas de processamento dos resultados. 
A leitura do texto e o cálculo dos dicionários correspondem à primeira etapa do processo, responsável por reformar e dividir o texto para a organização das Unidades de Contexto Elementar (UCEs). Essa etapa organiza os vocábulos, reduz as palavras e cria os dicionários.

Na segunda etapa, ocorrem o cálculo das matrizes de dados e a classificação das UCEs (cálculo de qui-quadrado medindo a importância das ligações com nível de significância de 5\%). Aqui as UCEs são selecionadas e ocorrem os cálculos para a formação das matrizes pela Classificação Hierárquica Descendente (CHD).

Na terceira etapa, realiza-se a descrição das classes de UCEs, com a definição e a descrição das classes em paralelo à Análise Fatorial de Correspondência (AFC). Por fim, na quarta etapa, ocorrem os cálculos complementares que estruturam as UCEs em cada classe. Dessa forma, é estabelecida a estruturação da Classificação Hierárquica Ascendente (CHA) e acontece a organização de outras informações que são exportadas para o relatório de análise (rapport détaillé).

Após os resultados fornecidos pelo software Alceste, os dados foram analisados com base na literatura e organizados na forma de quadros para mostrar a relação de variáveis presentes em cada uma das classes. Posteriormente, selecionaram-se fragmentos dos corpora para exemplificar e reafirmar a síntese realizada em cada classe.

Os 94 entrevistados (homens e mulheres de diferentes gerações) expressaram, por meio de um formulário semiestruturado, as suas satisfações, insatisfações e expectativas em relação à cidade. As indagações iniciais visaram obter respostas imediatas que revelassem a visão espontânea dos rurais acerca das questões propostas. No processamento da análise do software Alceste, o corpus referente às vantagens e desvantagens da cidade foi constituído de 188 UCls, totalizando 2.242 ocorrências, com 533 palavras diferentes, tendo, em média, quatro ocorrências por palavra. Para a análise que se seguiu, consideraram-se as palavras com frequência igual ou superior à média e $\operatorname{com} X^{2 \geq} 3,84$. Após a redução dos vocábulos às suas raízes, encontraram-se 84 palavras reduzidas e analisáveis e 194 UCEs (fragmentação do corpus de dados segundo critérios de pontuação e tamanho do banco de informações). A CHD aproveitou $80 \%$ total das UCEs do corpus, organizando-os em duas classes, que foram formadas pelas palavras mais representativas a partir do valor do qui-quadrado e da AFC.

O corpus sofreu uma divisão a partir da CHD, referente ao conteúdo verbal das imagens associadas à cidade, sistematizadas em duas classes. A primeira aglomeração foi denominada Classe 1 (Vantagens da cidade), e a segunda, Classe 2 (Desvantagens da cidade), tal como apresentado no Quadro 1. Para representar os significados presentes em cada classe, foram selecionadas as palavras com maior qui-quadrado, cálculo que indica a força de associação entre a palavra e a classe correspondente (Kronberger \& Wagner, 2002, p. 427). Para fins de contextualização, apresentaram-se as classes acompanhadas de suas respectivas palavras relevantes na sua constituição.

\section{RESULTADOS E DISCUSSÕES}

Esta seção apresenta os resultados das análises sobre as representações sociais dos rurais acerca da cidade, permitindo evidenciar a forma como o espaço citadino se configura no modo de vida e no cotidiano dos habitantes do campo. Assim, constitui um meio investigativo sobre suas necessidades sentidas, seus julgamentos de valor, bem como suas motivações ou seus descontentamentos que orientam suas relações com esses espaços.

\subsection{A representação espontânea dos rurais acerca da cidade}

Em relação à imagem espontânea da cidade, a Classe 1 ("Vantagens da cidade") englobou 115 UCEs. Selecionaram-se e analisaram-se 19 palavras, correspondentes a $74 \%$ do corpus. As palavras analisadas pelo software corroboraram as interpretações realizadas por Silveira \& Fiúza (2014) acerca das imagens que os rurais elaboram do campo e da cidade. Segundo as referidas autoras, a "definição" de cidade para os rurais estaria voltada para utilidade nela vislumbrada. Na pesquisa em questão, a cidade aparecia na representação dos rurais como um espaço associado ao cotidiano, sendo relacionada ao comércio, ao trabalho, ao ganho de dinheiro, ao acesso a serviços de saúde, e como um espaço de facilidades. Sartre et al. (2016), ao analisarem a mobilidade de agricultores familiares em áreas de frentes pioneiras da Amazônia, averiguaram que a busca pelas 
cidades está relacionada ao desejo de estudar para alcançar bons empregos. Conforme também encontraram Braga et al. (2014), essa representação apontaria para uma síntese das relações que os rurais elaboram a partir das suas necessidades e dos bens que consomem.

Quadro 1 - Dendrograma de classificação hierárquica.

\begin{tabular}{|c|c|c|c|}
\hline \multicolumn{2}{|c|}{$\begin{array}{c}\text { CLASSE } 1 \\
115 \text { UCES } \\
74 \%\end{array}$} & \multicolumn{2}{|c|}{$\begin{array}{l}\text { CLASSE } 2 \\
41 \text { UCES } \\
26 \%\end{array}$} \\
\hline \multicolumn{2}{|c|}{ Vantagens da cidade } & \multicolumn{2}{|c|}{ Desvantagens da cidade } \\
\hline Palavra / atributo & $x^{2}$ & Palavra / atributo & $x^{2}$ \\
\hline Coisas & 0,32 & Barulho & 0,58 \\
\hline Comprar & 0,21 & Violência & 0,47 \\
\hline Perto & 0,21 & Droga & 0,39 \\
\hline Fácil & 0,20 & Poluição & 0,32 \\
\hline Saúde & 0,17 & Roubo & 0,29 \\
\hline Precisa & 0,17 & Bagunça & 0,25 \\
\hline Sair & 0,16 & Espaço & 0,23 \\
\hline Lugar & 0,16 & Carro & 0,22 \\
\hline Emprego & 0,16 & Água & 0,16 \\
\hline Dinheiro & 0,15 & Ruim & 0,15 \\
\hline Trabalhar & 0,14 & & \\
\hline Casa & 0,14 & & \\
\hline Roça & 0,13 & & \\
\hline Conseguir & 0,12 & & \\
\hline Facilidade & 0,12 & & \\
\hline Oportunidade & 0,12 & & \\
\hline Posto de saúde & 0,11 & & \\
\hline Rápido & 0,11 & & \\
\hline Melhor & 0,11 & & \\
\hline
\end{tabular}

Fonte: inquérito por questionário semiestruturado realizado no município de Araponga/MG.

$\mathrm{Na}$ presente investigação, tal como nas pesquisas citadas anteriormente, os rurais caracterizaram a cidade como um "espaço de oportunidades", um "lugar para ganhar dinheiro", "para se conseguir trabalho", "ter acesso à saúde e mais facilidade para fazer as coisas", como se pode observar nas manifestações que se seguem:

Tem coisas ao redor, tudo é mais perto, tem oportunidade de emprego e de continuar um estudo diferenciado, oportunidade de conhecer lugares novos e de conseguir as coisas (Respondente 3, jovem, mulher, 17 anos). Salário todo mês, oportunidade de ter um emprego, tem rotina, o dinheiro vem mais fácil que na roça porque o trabalho não é tão pesado igual ao da roça (Respondente 37, adulta, 44 anos).

Principalmente as mulheres e os mais jovens destacaram a cidade como espaço capaz de "abrir os espíritos", como lugar de trabalho e de diversão. Gomes et al. (2015) constataram que foi por meio das mulheres e dos jovens que a cultura urbana penetrou com maior facilidade na sociedade rural da Zona da Mata mineira. Provavelmente, ambos os grupos se encontravam menos satisfeitos com sua situação de vida dentro da hierarquia social vigente no campo. Adrião (2006, p. 14), ao estudar as mudanças no modo de vida das famílias ribeirinhas ligadas à atividade pesqueira, observou que hábitos, costumes e valores difundidos pela cultura urbana passam a ser privilegiados especialmente pelos habitantes 
mais jovens. Essa perspectiva contrastante acerca da cidade por parte de indivíduos de diferentes gerações pode ser exemplificada pelos seguintes discursos

Ir muito na cidade te desvincula da sua atividade, tende a não valorizar aquilo que você tem. Se a pessoa tiver inclinação para mexer com droga, roubo, estas coisas, acaba tirando a pessoa do rumo (Respondente 7, idoso, 64 anos). Melhora na questão do conhecimento, se a gente ficar só aqui, parado, não vai saber das coisas que acontece lá fora. A gente vai conversando ali, aprende alguma coisa, pega novas ideias, práticas. A pessoa que não anda conhece pouco as coisas (Respondente 48, jovem, homem, 20 anos).

No geral, não apenas as mulheres e os jovens manifestaram uma representação positiva da cidade. Esse mesmo olhar foi encontrado nos demais grupos. No entanto, tal visão é mais expressiva entre as mulheres e os jovens:

Na cidade você tem conhecimento das coisas, dá para conhecer várias pessoas e lugares diferentes, tem dinheiro certeiro todo mês, tem a carteira assinada, mais recurso, mais oportunidade pra fazer um curso que pensa (Respondente 74, adulto, 32 anos). 0 ritmo da vida, o tempo passa rápido, tem movimento (Respondente 89, adulto, 36 anos). As coisas chegam mais rápido na cidade, tecnologia, informação. Tem mais chance de arrumar um emprego, você está perto dos postos de saúde, perto de transporte pra qualquer coisa, até perto da igreja (Respondente 53, adulto, 35 anos). Tem uma condição de vida melhor, a tecnologia é maior para usar (Respondente 18, jovem, homem, 17 anos).

As narrativas relativas à cidade a caracterizam, portanto, como lugar de maior intercâmbio, tal como o encontrado por Silveira \& Fiúza (2014), que revelaram o destaque dado pelos rurais à cidade como mediadora dos objetos e das pessoas, como um espaço com um ritmo de vida mais acelerado. Essas funções foram evidenciadas na Classe 1, apresentada no Quadro 1, no qual as palavras, "comprar", "perto", "rápido", "posto de saúde" e "coisas" apareceram associadas à produção, à oferta e à proximidade dos serviços bancários, de saúde, de educação e de transporte.

Lá tem mais facilidade nas redondezas, tudo é mais perto, se você vai comprar alguma coisa é pertinho, porque no nosso lugar não tem por exemplo loja que acha de tudo (Respondente 12, adulta, 30 anos). Tem hospital mais perto, banco, as escolas ainda são mais fáceis de acessar, tem mais facilidade para levar a vida (Respondente 34, adulta, 43 anos).

Em suma, a imagem positiva da cidade foi destacada pelos rurais em função de se constituir como polo aglutinador das decisões comerciais, econômicas e políticas. Também Bonomo et al. (2013) ressalta que a cidade, quando avaliada pelos rurais, era valorizada pelos seus recursos e serviços, pelas comodidades fornecidas, pela oferta de trabalho e pelo comércio. Os rurais manifestaram sentir a cidade como parte do seu cotidiano, em função de ela fornecer os elementos fundamentais à sobrevivência das pessoas do lugar. Percebe-se, assim, que para os rurais a cidade tem um caráter de complementariedade em relação ao campo, estando integrada às suas necessidades e demandas, tal como pode ser observado nas palavras do respondente 7 :

A cidade é importante para comprar o que você não consegue produzir ou fabricar, lá tem as coisas mais perto. É isso, ela oferece condições para você comprar mais, se você tiver o dinheiro, porque, se não tiver, não vai adiantar nada não. Mas, hoje, tudo que você compra nem precisa ir no lugar mais, hoje você compra pelo telefone, pela internet, eles entregam na sua porta, do mesmo preço que vende na cidade, não tem muita diferença, se você tiver dinheiro pra comprar, você nem precisa sair de casa mais, você sai de casa quando quer. Aqui agora tem de tudo, telefone, internet. Eu tenho também (Respondente 7, idoso, 64 anos).

Nessa narrativa, a ênfase se dirige ao processo de desterritorialização dos serviços oferecidos nas pequenas cidades, conforme destacado por Kageyama (2008). Os dados levantados na presente pesquisa evidenciam que o acesso à internet permite aos rurais 
atender às suas necessidades de forma deslocalizada. Nesse sentido, Delgado \& Leite (2011) afirmam que a identidade territorial dos habitantes do campo também está associada com as fragilidades identificadas nesse espaço. Dessa forma, expandem-se os vínculos territoriais dos rurais para além do município onde residem.

Por outro lado, a cidade apresenta complicações relativas à vida cotidiana, correspondendo a uma certa desumanidade na representação dos rurais. Todavia, os dados contidos no Quadro 1 indicam que a imagem negativa da cidade não é tão expressiva quanto a imagem positiva. Tal interpretação se confirma com a observação de que apenas $26 \%$ do corpus apresentam aspectos relacionados às desvantagens da cidade, enquanto as vantagens representam 74\% do corpus. A análise da Classe 2 (Quadro 1), relativa às “Desvantagens da cidade", envolveu 41 UCEs, com 10 palavras analisadas, as quais revelaram os aspectos repulsivos da vida urbana interferindo em seu caráter atraente, tais como "barulho", "violência", "droga", "poluição", "roubo" e "bagunça".

A falta de espaço foi também destacada negativamente pelos rurais, revelando o seu incômodo com os carros e o intenso movimento das cidades. Coincidentemente ao encontrado por Bonomo et al. (2013), na presente pesquisa a representação dos rurais sobre a cidade foi antagônica em relação ao campo nos aspectos concernentes à natureza. A água da cidade comparada com aquela do campo foi considerada de qualidade ruim, além de ser paga. Esse pagamento por um bem básico é, inclusive, associado à perda de independência que a vida na cidade gera. Refere-se à compra de tudo o que se precisa para viver. As narrativas que se seguem retratam essas desvantagens da cidade na representação dos rurais.

Poluição, água ruim, barulho, muita violência, não tem liberdade na hora que quer (Respondente 29, jovem, homem, 21 anos). Bagunça de gente, de movimento, de barulho (Respondente 24, jovem, mulher, 24 anos). Fico sufocada, é pouco espaço e muita agitação (Respondente 30, idosa, 68 anos). Roubo, uso de muita droga, poluição. Paga água, iluminação de rua, os impostos são mais caros e a convivência é difícil entre as pessoas (Respondente 49, jovem, homem, 15 anos). A desvantagem da cidade é porque a pessoa tem tudo que quer, mas a maioria das coisas que eles precisa depende do pessoal da roça, por exemplo, alimento, eles não consegue produzir pra eles mesmo, então tudo que quer acaba tendo que comprar. O modo de viver também é mais difícil, a pessoa fica mais presa dentro de casa, a vida é mais cansativa (Respondente 10, jovem, homem, 17 anos). Tem que comprar tudo pra casa, a cidade tem um alto custo de vida. Se não tiver dinheiro, não tem como viver (Respondente 18, jovem, homem, 17 anos). Para criar família é complicado, tem mais violência, se a pessoa não tiver salário bom, não tem como viver, custo de vida é mais alto, deslocamento é mais difícil, trânsito caótico (Respondente 59, jovem, mulher, 24 anos).

Assim, a representação imediata dos rurais sobre a cidade indica a valoração de aspectos positivos e negativos, em balanço realizado de forma consciente e ponderada. Nessa avaliação espontânea e imediata, os rurais revelaram, portanto, tal como o destacado na pesquisa de Silveira \& Fiúza (2014), que estabelecem um caráter complementar entre a vida no campo e na cidade. Avaliavam o espaço citadino como atrativo em função, principalmente, dos aspectos relacionados ao trabalho remunerado, à escolaridade, ao consumo e às possibilidades de acesso às tecnologias de informação e comunicação. Contudo, as comodidades encontradas na cidade não deixam, segundo a representação dos rurais, de revelar aspectos negativos que desvirtuam a simplicidade da vida no campo. Essa perda de autonomia relaciona-se, principalmente, às exigências de uma formação profissional e às crescentes necessidades de consumo.

Destaque negativo em relação à cidade se refere igualmente à poluição, ao excesso de barulho, à falta de ar puro e água de qualidade. Os respondentes identificaram ainda problemas como o uso de drogas e violência. Portanto, este estudo evidencia o papel da cidade para os rurais, os quais expressam satisfação, mas também retratam a cidade como violenta e pobre em termos de relações pessoais. Por fim, em relação à avaliação espontânea, a valoração positiva acerca da cidade foi muito mais expressiva que a negativa. A propósito, a pesquisa realizada por Rambaud (1973) destacou que os rurais manifestavam o desejo de assumir um modo de vida mais urbano, em virtude de concebê-lo como menos "sofrido" e "rude". 
O gradativo e heterogêneo processo de transformação da sociedade rural não se estabelece de forma impositiva, como defende Burke (2003) em seu estudo sobre o hibridismo cultural. Tanto para Burke (2003) como para Rambaud (1973), o processo de urbanização é, antes de tudo, mental e se manifesta de forma segmentada e diferenciada em termos de grupos e indivíduos em dada sociedade. Cada indivíduo monta o seu próprio "canevas", uma espécie de tela (representando a estrutura social) sobre a qual cada um pode imprimir traços e contornos com seu estilo pessoal, escolhendo o que lhe convém absorver da cultura urbana, a partir de suas referências e identidade.

Conforme Silveira et al. (2013), Rambaud teria enfatizado, na referida pesquisa da sociedade rural francesa na década de 1960, a diversidade de significados e práticas interativas dos rurais com a cultura urbana, destacando que, enquanto jovens e mulheres manifestavam maior abertura para absorver determinados comportamentos urbanos, homens adultos e idosos reagiam de maneira mais hostil à incorporação de elementos da cultura urbana, oferecendo resistência à sua integração no seu modo de vida. Essa evidência da heterogeneidade de intensidade com que a cultura urbana era absorvida nas sociedades rurais apontava para o fato de que o processo de urbanização, tal como advogou Veiga (2004), multiplicava os centros de interesse dos rurais, embora provocasse também reações que ora os aproximava de determinados grupos urbanos, ora os afastava. Portanto, a urbanização influencia no campo de forma até mesmo contraditória (Veiga, 2004). Contudo, mesmo que de forma diversificada e com ritmos próprios, o processo de urbanização se manifesta tanto na representação coletiva dos rurais quanto no mundo material, no que diz respeito aos artefatos relacionados ao mundo do trabalho, à modernização da agricultura, via industrialização das atividades produtivas como tratou Silva (1996), à esfera doméstica e aos modos de vida, de forma geral.

\subsection{A representação reflexiva dos rurais acerca da cidade}

Enquanto a estratégia das respostas espontâneas buscou apreender as representações dos rurais acerca da cidade e do campo sob a perspectiva daquilo que se encontrava consolidado em termos de valores e visão social de mundo, o estímulo à reflexão busca elementos para analisar o significado das representações dos entrevistados. Assim, quanto às assertivas que os rurais manifestaram "concordância total" (Tabela 1) estão afirmações referentes à vida cotidiana, tais como: "os meios de transporte diminuem a distância entre a zona rural e a cidade", "os equipamentos comprados na cidade facilitam o trabalho na zona rural" e "na cidade existe maior acesso à informação". Os respondentes manifestaram concordância total também em relação a outras afirmações que se referiam a julgamentos de valor, tais como: "as pessoas da roça também fazem parte da cidade", "o dinheiro das pessoas da roça enriquece as pessoas da cidade", "assistir televisão e escutar rádio muda o jeito das pessoas que vivem na zona rural" e "estudar faz a pessoa subir de vida".

Tabela 1 - Nível de concordância total com assertivas sobre a representação reflexiva do campo e da cidade.

\begin{tabular}{cc} 
Assertivas & $\begin{array}{c}\text { Concordo } \\
\text { totalmente }\end{array}$ \\
Os meios de transporte diminuem a distância entre a zona rural e a cidade & $95,7 \%$ \\
A cidade faz as pessoas gastarem mais & $94,7 \%$ \\
Os equipamentos comprados na cidade facilitam o trabalho na zona rural & $93,6 \%$ \\
Na cidade existe maior acesso à informação & $92,6 \%$ \\
As pessoas da roça também fazem parte da cidade & $92,6 \%$ \\
A cidade muda o jeito de as pessoas se alimentarem & $89,4 \%$ \\
As pessoas que vivem na cidade têm mais oportunidade de estudar e ter uma profissão que & $86,2 \%$ \\
a ida p̀ cidade desperta o interesse de comprar mais roupas e calçados para uso pessoal & $84 \%$ \\
Os alimentos comprados na cidade tornam mais fácil o preparo das refeições & $83 \%$ \\
\hline
\end{tabular}


Tabela 1 - Continuação...

A ida à cidade desperta o interesse de comprar mais eletrodomésticos e móveis para a casa

O jovem prefere viver na cidade do que na zona rural

O dinheiro das pessoas da roça enriquece as pessoas da cidade

A ida à cidade desperta o interesse de comprar celular, computador e usar a internet

Assistir televisão e escutar rádio muda o jeito das pessoas que vivem na zona rural

As casas da zona rural estão parecidas com as casas da cidade

Fonte: inquérito por questionário semiestruturado realizado no município de Araponga/MG.

Tal como ocorreu nas respostas espontâneas, as reflexivas também confirmaram a imagem da cidade para os rurais como lugar para resolver problemas, como local de consumo, onde a vida é fácil e apresenta muitas oportunidades. Contudo, a vida na cidade também foi percebida como não tendo a independência, em termos de autoprodução, que o campo apresenta. Se, por um lado, a cidade é vista como um lugar em que a vida é mais fácil, pois tudo se compra, por outro lado os rurais destacaram que essa lógica consumista torna as pessoas na cidade muito mais dependentes.

Você pingou fora de casa, já tá gastando. Todo jeito que vira, tá gastando (Respondente 4, idoso, 68 anos). Às vezes você não vai com a intenção de comprar, mas vê uma coisa e aí já viu, acaba comprando (Respondente 52, adulta, 37 anos). Como se diz, tudo que não vê passa sem ele, agora vendo, sempre acaba comprando (Respondente 14, adulta, 39 anos). Você vê mais coisas e, se algum conhecido tiver, a pessoa pensa: se fulano tem, eu quero ter também, eu também vou comprar (Respondente 18, jovem, homem, 17 anos). Tudo que os olhos não vê, o coração não deseja, a pessoa olha as coisas e caba querendo comprar (Respondente 7, idoso, 64 anos). Se for muito na cidade, compra mesmo, se eu não for, não vejo, fico quieta por aqui, eu fico com a que tem (Respondente 32, idosa, 70 anos).

A importância atribuída à compra de tecnologias de informação e comunicação revela a proximidade com o modo de vida urbano. Dos respondentes, $74 \%$ concordaram com a afirmativa "a ida à cidade desperta o interesse de comprar celular, computador e usar a internet".

O celular ajuda demais, ele faz uma desordem, na mesma hora que você está aqui, você está em São Paulo (Respondente 4, idoso, 68 anos).

No que diz respeito ao trabalho, a imagem que os respondentes manifestaram da relação entre o campo e a cidade revela um sentimento de subordinação e exploração: $78,7 \%$ dos respondentes expressaram a sua total concordância em relação à afirmativa: "o dinheiro das pessoas da roça enriquece as pessoas da cidade".

Quando a gente vende aqui, vende baratinho, chega na cidade, eles vendem caro. Pra eles comprar, tem um preço, para vender é outro (Respondente 25, adulta, 35 anos). Tudo que colhe na roça, leva pra cidade. Na época da panha do café, esses comerciantes ficam tudo doido. Se café desse duas vezes por ano, povo ficava milionário (Respondente 44, adulto, 57 anos).

Contudo, mesmo manifestando a percepção de formas de exploração nas relações de troca estabelecidas com a cidade, os respondentes não se viam de forma alguma excluídos da dinâmica citadina. Acreditavam participar na constituição das cidades, sendo que 92,6\% concordaram totalmente com a assertiva "as pessoas da roça também fazem parte da cidade". O estudo de Rye (2006) acerca das representações dos rurais sobre a cidade revelou que estes últimos se sentiam como fazendo parte de um mesmo contexto. Os rurais consideravam a 
cidade como um prolongamento de sua própria sociedade, como se pode constatar nas narrativas a seguir:

Não tem ninguém que não faz parte, pra você vê, até quando nós morremos, nós vamos pra lá (Respondente 4, idoso, 68 anos). A gente faz parte porque precisa muito dela, do mesmo jeito que eles precisam das coisas que a gente manda pra eles (Respondente 18, jovem, homem, 17 anos). Não é porque está lá na roça que está separado, a gente também faz parte da cidade (Respondente 55, adulta, 42 anos).

Apesar de $92,6 \%$ dos rurais terem avaliado que também faziam parte da cidade, esse vínculo foi percebido por $60,6 \%$ dos respondentes como associado a um certo preconceito dos citadinos em relação às pessoas do meio rural, tal como revela as manifestações a seguir.

Nem sempre trata bem, há umas demagogias, é o jeca do mato. Tem aquele negócio: o da roça nem vem ali (Respondente 7, idoso, 64 anos). Algumas pessoas da cidade tratam a gente igual bicho por conta das nossas mãos calejadas (Respondente 57, jovem, mulher, 22 anos).

Mas, independentemente do preconceito, convém insistir que os rurais se sentiam parte da cidade e manifestaram sentir a influência dos hábitos urbanos. Diante da assertiva "os alimentos comprados na cidade facilitam o preparo das refeições", $83 \%$ dos respondentes concordaram totalmente com tal afirmativa. Essa visão reforça a perspectiva de autores como Braga et al. (2015) que mencionam em seus estudos que o modo de vida rural incorpora cada vez mais traços do modo de vida urbano.

A gente compra um frango lá, ele já vem praticamente pronto, no jeito. Agora, na roça, a gente recria uns frangos de granja, aí tem que preparar, tem que matar, limpar, picar, aí eu acho que o alimento da cidade nesta parte facilita. Apesar dele vir gelado de lá, a gente não sabe o jeito que ele foi tratado (Respondente 6, jovem, homem, 26 anos). Facilita muito, porque já vem arrumado, cozido, mastigado, é só engolir (Respondente 28, adulto, 50 anos).

A proximidade que os rurais manifestaram sentir em relação ao modo de vida urbano se reforça ainda com a visão sobre a penetração da racionalidade produtiva no mundo do trabalho no meio rural, o que foi realçado por Cortês \& D'Antona (2016) na fronteira agrícola amazônica. A aprovação da penetração da tecnologia no trabalho agrícola chega perto da unanimidade entre os rurais, tal como também apontaram Ortega \& Jesus (2011, p. 772) ao estudarem as transformações na estrutura produtiva do café no Cerrado mineiro. Dos respondentes, 94\% concordaram com a afirmação de que "os equipamentos comprados na cidade facilitavam o trabalho na zona rural". Segundo Candido (1997), as relações com base na produtividade passaram a se apoiar mais no conhecimento técnico-científico. Essa mudança é apresentada da seguinte forma por uma das interlocutoras:

Na roça hoje todo mundo tem uma maquininha. Difícil ver alguém voltando de serviço com enxada na mão. Se não ver uma zoeira é porque o povo não está na roça trabalhando. Toda maneira ajuda sim, folga demais, porque rende o serviço (Respondente 62, idosa, 65 anos).

Se o trabalho agrícola é reconhecido como tendo incorporado a tecnologia vinda da cidade, tornando-se menos penoso, mais da metade dos respondentes discordaram da afirmação de que "o modo de trabalhar na zona rural estava parecido com o modo de trabalhar na cidade". Dos respondentes, 53,2\% discordaram totalmente de tal afirmativa, considerando que o trabalho no meio rural está em uma posição inferior quando comparado ao trabalho na cidade.

Na cidade as pessoas trabalham no computador, só de boa. Na roça, mesmo quando a gente trabalha usando uma máquina, é um trabalho muito mais difícil, sofre mais, trabalha debaixo de sol, chuva, poeira, é bem diferente do da cidade (Respondente 6, jovem, 
homem, 26 anos). Na roça trabalha de qualquer maneira, põe um boné na cabeça e parte. $\mathrm{Na}$ cidade tem que ficar aprontando, tem que sair arrumadinho para o serviço (Respondente 68, jovem, mulher, 29 anos).

Contudo, se, em relação ao trabalho, as diferenças entre a realidade do campo e da cidade foram avaliadas de forma contrastante, em outros aspectos como o acesso aos meios de transporte os rurais consideraram estar havendo uma aproximação do seu modo de vida com aquele dos citadinos. Dos respondentes, 96\% concordaram com a afirmação "os meios de transporte diminuem a distância entre a zona rural e a cidade".

Porque facilitou bastante, hoje todo mundo tem um modo de condução para ir. Tem o ônibus que leva e que busca na cidade, o modo é mais fácil um pouco para sair, mesmo quem não tem condução própria para ir (Respondente 6, jovem, homem, 26 anos). Na verdade parece que encurta mesmo, porque a pé tudo fica mais longe. Ai de nós se não tivesse o meio de transporte. Povo não anda mais a pé não (Respondente 20, adulta, 31 anos). Carro e moto aqui está a mesma coisa que na cidade, tem o mesmo movimento (Respondente 32, idosa, 70 anos).

Pode-se observar que as respostas obtidas com estímulo reflexivo seguem em confluência com as respostas espontâneas, o que indica que as representações dos rurais se constituem como uma visão social de mundo, que expressa os valores e as perspectivas da coletividade, como apontam Brandão et al. (2014), tornando-se também responsável pela estruturação dos sistemas socioespaciais (Domingues, 1999). Os rurais expressaram a visão segundo a qual a cidade é parte integrante da sua vida. Tal fato não pode ser interpretado, entretanto, como significando que se sentem urbanos. A forma contrastante com que opõem a vida no campo à vida na cidade, segundo Silveira et al. (2015), aponta para uma construção de identidade. Trata-se do sentimento de uma pessoa do meio rural mantendo um significado, em forte sentido relacional.

O espaço citadino, na ótica dos rurais, figura como integrante das suas vidas. Porém, é evidente na oposição "nós" e "eles", a qual pode ser observada na interpretação que fazem da afirmação: "pessoas da cidade tratam bem as pessoas da roça quando estas vão à cidade". A concordância parcial com essa afirmação foi superior a $60 \%$, indicando a percepção por parte dos rurais de uma separação identitária de caráter hierárquico, revelada na discordância com a afirmação de que os citadinos os tratariam bem. Como o observado na Tabela 2, a cidade é vista pelos rurais como lugar de consumo, de busca de trabalho, de serviços, mas também como lugar que pode "estragar as pessoas".

Tabela 2 - Nível de concordância parcial com assertivas sobre a representação reflexiva do campo e da cidade.

\begin{tabular}{ccc|} 
Assertivas & $\begin{array}{c}\text { Concordo } \\
\text { totalmente }\end{array}$ & $\begin{array}{c}\text { Concordo } \\
\text { parcialmente }\end{array}$ \\
\hline $\begin{array}{c}\text { A ida à cidade faz a pessoa comprar mais equipamentos agrícolas e insumos } \\
\text { para a propriedade }\end{array}$ & $43,6 \%$ & $37,2 \%$ \\
Ir muito à cidade estraga a pessoa & $41,5 \%$ & $22,3 \%$ \\
Trabalhar na cidade dá mais segurança à pessoa que trabalhar na roça & $41,5 \%$ & $17 \%$ \\
Ir muito à cidade melhora a pessoa & $40,4 \%$ & $19,1 \%$ \\
As pessoas da cidade tratam bem as pessoas da roça quando estes vão à & $28,7 \%$ & $60,6 \%$ \\
$\quad$ cidade & $28,7 \%$ & $23,4 \%$ \\
\hline
\end{tabular}

Fonte: inquérito por questionário semiestruturado realizado no município de Araponga, MG.

Assim, tal como verificado por Silveira et al. (2015), a percepção dos rurais em relação à cidade tem caráter relacional. A identidade rural não nega a utilidade da cultura urbana e dos serviços citadinos, mas expressa também o reconhecimento da diferença entre o modo de vida na "roça" e na "cidade". Conforme Bonomo et al. (2013), as antinomias que operam nos 
princípios organizadores das representações de rural e cidade fornecem evidências de sua interdependência constitutiva e funcional. A própria sociedade rural, por meio da sua representação, expressa sentir o seu vínculo com a realidade citadina em função das experiências entre esses dois universos. Nas respostas obtidas com estímulo reflexivo, um expressivo número de rurais manifestou a percepção relativa ao gradual processo de aproximação entre o modo de vida urbano e rural. Dos respondentes, 52\% concordaram total ou parcialmente com as afirmativas de que "o modo de viver na zona rural está parecido com o modo de viver na cidade" e que "as casas da zona rural estão parecidas com as casas da cidade".

Mesmo quem está na roça, hoje, questão de alimentação, vestimenta, boas morada, está mais parecido com a cidade. Já foi o tempo que as casa na roça era ruim, povo andava mal vestido, comia o que tinha em casa. Mas, agora virou moda, de primeiro as coisas eram bem grosseiras, simples, hoje ninguém fica pra trás. O povo está sempre melhorando mais, porque você traz o conforto pra roça (Respondente 62, idosa, 65 anos).

Por fim, cabe ressaltar que os resultados apresentados reforçam a interpretação de integração entre os processos socioeconômicos e culturais contemporâneos de escala mundial que envolvem as realidades socioespaciais do campo e da cidade. De fato, são múltiplas as experiências que a sociedade rural vem passando em decorrência do processo de estreitamento das relações entre o campo e a cidade.

\section{CONSIDERAÇÕES FINAIS}

As mudanças que atravessam as sociedades contemporâneas, especialmente aquelas que vêm sendo experimentadas no campo, constituem o pano de fundo deste trabalho. Essas transformações revelam os contornos de uma sociedade em intensa relação material e imaterial com o espaço citadino. A proposição teórico-metodológica adotada neste estudo constitui recurso investigativo para a análise das tensões, contradições e conflitos relativos aos pontos positivos e negativos quanto à vida na cidade e no campo, segundo o julgamento dos próprios rurais, de modo espontâneo e reflexivo. As representações referentes à cidade e ao campo, manifestadas pelos moradores do campo de um pequeno município produtor de café, situado na Zona da Mata mineira, sobre as experiências cotidianas estabelecidas com a cidade permitem constatar uma percepção objetiva da cidade, em que sua funcionalidade foi realçada de forma positiva, mas também afloraram os seus aspectos negativos. A cidade foi definida como um espaço que proporciona oportunidades de formação profissional, seguridade financeira, facilidade de acesso a serviços e reunião de pessoas. Em contrapartida, os rurais também reconheceram que a experiência urbana carrega certa desumanidade, uma vez que as relações face a face são frágeis e ocorre violência, uso de drogas e poluição. Ademais, a necessidade de grande consumo torna as pessoas dependentes.

Torna-se evidente ainda que os habitantes do campo compreendem que o par dialético campo-cidade constitui dois espaços articulados e interdependentes, manifestando sentir a influência dos hábitos urbanos. Porém, é notório que as diferentes representações sociais do espaço citadino revelam uma separação identitária de caráter hierárquico. A contraposição entre o "ser da roça" e "ser da cidade" se constitui em um demarcador identitário que delimita formas de pertencimento antagônicas entre si. Embora os rurais tenham manifestado sentir a cidade como parte da sua vida, não se sentiam da cidade, tampouco se reconheciam sendo valorizados pelos citadinos. Dessa forma, a constituição identitária dos rurais se elaborou a partir do reconhecimento do pertencimento ao seu espaço de vida, que ganhou uma dimensão de enraizamento em relação à funcionalidade do espaço citadino.

Assim, o artigo evidenciou as representações coletivas dos habitantes do campo em um pequeno município de economia agrícola como forma de refletir os anseios e as tensões criadas acerca da realidade citadina. A análise das representações sociais sobre a relação campo-cidade foi o foco analítico adotado neste trabalho para a compreensão das intensas interações estabelecidas entre a vida no campo e a vida na cidade. As mudanças observadas no meio rural e em pequenos vilarejos na contemporaneidade revelam os contornos de uma sociedade com intensa troca material e imaterial com o espaço citadino, conformando uma 
densa agenda para futuras pesquisas. Com efeito, os meandros das representações sociais aqui exploradas podem contribuir para a reformulação decisiva de instrumentos de intervenção política para o desenvolvimento dos espaços rurais.

\section{REFERÊNCIAS BIBLIOGRÁFICAS}

Adrião, D. (2006). Pescadores de sonhos: um olhar sobre as mudanças nas relações de trabalho e na organização social entre as famílias dos pescadores diante do veraneio e do turismo balnear em Salinópolis, Pará. Boletim do Museu Paraense Emílio Goeldi. Ciências Humanas, 1(2), 11-21. Recuperado em 23 de outubro de 2016, de http://www.scielo.br/pdf/bgoeldi/v1n2/v1n2a02.pdf

Alba, M. (2004). El método ALCESTE y su aplicación al estúdio de las representaciones Sociales del espacio Urbano: El caso de la Ciudad de México. Papers on Social Representations, 13(1), 1-20.

Araújo, L. F., Coutinho, M. P. L., \& Santos, M. F. S. (2006). O idoso nas instituições gerontológicas: um estudo na perspectiva das representações sociais. Psicologia e Sociedade, 18(2), 89-98.

Bolfarine, H., \& Bussab, W. O. (2005). Elementos de amostragem. São Paulo: Edgar Blucher.

Bonomo, M., Souza, L., Melotti, G., \& Palmonari, A. (2013). Princípios organizadores das representações de rural e cidade. Revista Sociedade e Estado, 28(1), 91-118.

Braga, G. B., Fiúza, A. L. C., \& Pinto, N. M. A. (2014). Os padrões de consumo no campo e na cidade: a aproximação entre os modos de vidas de citadinos e rurais. Estudios Rurales, 1, 64-80. Recuperado em 7 de janeiro de 2015, de https://dialnet.unirioja.es/descarga/articulo/4805352.pdf

Braga, G. B., Fiúza, A. L. C., \& Remoaldo, P. C. (2015). Por uma caracterização do território através do modo de vida rural e/ou urbano. Por Extenso: Boletim de Pesquisa do Programa de Pós-Graduação em Extensão Rural, 7, 136-153.

Brandão, V. A. B., Riveira, I. S., Maseda, R. C., \& Ferreira Neto, J. (2014). Análise social dos fatores que influenciam o desenvolvimento e o planejamento de assentamentos rurais: os casos dos Municípios de Cervantes e Guitiriz na Galícia. DADOS - Revista de Ciencias Sociales, 57(3), 711-744. Recuperado em 6 de janeiro de 2017, de http://www.scielo.br/pdf/dados/v57n3/0011-5258-dados57-03-0711.pdf

Burke, P. (2003). Hibridismo cultural. São Leopoldo, Ed. da Unisinos.

Candau, J. (2011). Memória e identidade. São Paulo: Editora Contexto.

Candido, A. (1997). Os parceiros do Rio Bonito: estudo sobre o caipira paulista e a transformação dos seus modos de vida (8 ${ }^{\mathrm{a}}$ ed.). São Paulo: Ed 34.

Carneiro, M. J. (2012). "Rural” como categoria de pensamento e categoria analítica. In M. J. Carneiro (Org.), Ruralidades contemporâneas: modos de viver e pensar o rural na sociedade brasileira (pp. 2350). Rio de Janeiro: Mauad X, FAPERJ.

Cortês, J. C., \& D’Antona, A. O. (2016). Fronteira agrícola na Amazônia contemporânea: repensando o paradigma a partir da mobilidade da população de Santarém-PA. Boletim do Museu Paraense Emílio Goeldi. Ciências Humanas, 11(2), 415-430. Recuperado em 5 de fevereiro de 2017, de http://www.scielo.br/pdf/bgoeldi/v11n2/1981-8122-bgoeldi-11-2-0415.pdf

Delgado, N., \& Leite, S. (2011). Políticas de desenvolvimento territorial no meio rural brasileiro: novas institucionalidades e protagonismo dos atores. DADOS - Revista de Ciencias Sociales, 54(1), 431-473. Recuperado em 14 de dezembro de 2016, de http://www.scielo.br/pdf/dados/v54n2/v54n2a07.pdf

Domingues, J. M. (1999). Sociologia da cultura, memória e criatividade social. DADOS - Revista de Ciencias Sociales, 42(2), 303-339. Recuperado em 19 de abril de 2015, de http://www.scielo.br/scielo.php?script=sci_arttext\&pid=S0011-52581999000200004

Gomes, N. M. F., Fiúza, A. L. C., Pinto, N. M. A., \& Remoaldo, P. C. C. (2015). A mobilidade socioespacial dos rurais e suas expressões citadinas: uma análise do município de araponga, MG. Por Extenso: Boletim de Pesquisa do Programa de Pós-Graduação em Extensão Rural, 7, 118-126.

Hespanhol, R. A. M. (2013). Campo e cidade, rural e urbano no Brasil contemporâneo. Mercator (Fortaleza), 12(2), 103-112.

Instituto Brasileiro de Geografia e Estatística - IBGE (2010). Censo demográfico de 2010. www.ibge.gov.br. Jodelet, D. (2001). As representações sociais (Tradução, Lilian Ulup). Rio de Janeiro: EdUERJ.

Kageyama, A. (2008). Desenvolvimento rural: conceitos e aplicações ao caso brasileiro. Porto Alegre, Editora da UFRGS. 
Kronberger, N., \& Wagner, W. (2002). Palavras-chave em contexto: análise estatística de textos. In M. W. Bauer \& G. Gaskell (Orgs.), Pesquisa qualitativa com texto, imagem e som (pp. 416-441). Petrópolis: Vozes.

Miranda, E. L., Fiuza, A. L. C., \& Doula, S. M. (2016). O olhar dos agricultores familiares do município de Araponga-MG sobre sua organização social e produtiva: uma discussão pautada nas representações sociais. Extensão Rural, 23(4), 7-23. Recuperado em 24 de agosto de 2017, de https://periodicos.ufsm.br/extensaorural/article/view/21260/pdf

Moscovici, S. (2010). Representações sociais: investigações em psicologia social (7ª ed.). Petrópolis: Editora Vozes.

Ortega, A. C., \& Jesus, C. M. (2011). Território café do cerrado: transformações na estrutura produtiva e seus impactos sobre o pessoal ocupado. Revista de Economia e Sociologia Rural, 49(3), 771-800. Recuperado em 14 de janeiro de 2013, de http://www.scielo.br/pdf/resr/v49n3/a10v49n3.pdf

Pereira, J. L. G. (2004). Entre campo e cidade: amizade e ruralidade segundo jovens de Nova Friburgo. Estudos Sociedade e Agricultura, 12(2), 322-352. Recuperado em 19 de junho de 2013, de http://r1.ufrrj.br/esa/V2/ojs/index.php/esa/article/viewFile/253/249

Pereira, V. C., \& Almeida, J. (2015). Relações entre a atividade carbonífera e o rural em Candiota, RS, Brasil: análises sobre representações sociais em um contexto de dilemas sobre a energia. Revista de Economia e Sociologia Rural, 53(1), 127-142. Recuperado em 27 de setembro de 2015, de http://www.scielo.br/pdf/resr/v53n1/0103-2003-resr-53-01-00127.pdf

Rambaud, P. (1973). Société Rurale et Urbanisation ( $2^{\mathrm{a}}$ ed.). Paris: Ed. du Seuil.

Reinert, M. (1986). Un logiciel d'analyse lexicale: ALCESTE. Les Cahiers de l'Analyse des Donnees, 4, 471 484.

Reinert, M. (1993). Lex mondes lexicaus et leur logique à travers I' analyse statistique d'un corpus d'un récits de cauchemars. Langage \& Société, 66, 5-39.

Rye, J. F. (2006). Rural youth's images of the rural. Journal of Rural Studies, 22(4), 409-421. Recuperado em 13 de maio de 2013, de http://www.sciencedirect.com/science/article/pii/S0743016706000040

Sartre, X. A., Marin, J. O. B., Assis, W. S., Lopes, R. S., \& Veiga, I. (2016). Mobilidades geográficoprofissionais de duas gerações de agricultores familiares assentados na Amazônia oriental. Boletim do Museu Paraense Emílio Goeldi. Ciências Humanas, 11(1), 17-32. Recuperado em 3 de janeiro de 2017, de http://www.scielo.br/pdf/bgoeldi/v11n1/1981-8122-bgoeldi-11-1-0017.pdf

Sêga, R. A. (2000). O conceito de representação social nas obras de Denise Jodelet e Serge Moscovici. Anos 90: Revista do Programa de Pós-graduação em História da Universidade Federal do Rio Grande do Sul, 8(13), 128-133.

Silva, J. G. (1996). O novo rural brasileiro. Campinas: Editora da UNICAMP.

Silveira, L. N., \& Fiúza, A. L. C. (2014). Roça e os múltiplos sentidos para o rural no Brasil. Antropolítica: Revista Contemporânea de Antropologia, 2, 261-285.

Silveira, L. N., Coutinho, E., \& Fiúza, A. L. C. (2013). A atualidade da obra sociedade rural e urbanização, de Placide Rambaud, para a compreensão das transformações do campo no brasil. Estudos Sociedade e Agricultura, 21, 160-179. Recuperado em 16 de agosto de 2014, de http://r1.ufrrj.br/esa/V2/ojs/index.php/esa/article/view/363/359

Silveira, L. N., Fiúza, A. L. C., Silva, D. M., \& Maffra, R. (2015). Roça, uma marca registrada: o processo de valorização do rural na sociedade brasileira. Por Extenso: Boletim de Pesquisa do Programa de PósGraduação em Extensão Rural, 7, 154-162.

Veiga, J. E. (2004). A dimensão rural do Brasil. Estudos Sociedade e Agricultura, 12(1), 71-94. Recuperado em 27 de outubro de 2010, de http://r1.ufrrj.br/esa/V2/ojs/index.php/esa/article/view/246/242

Wanderley, M. N. B. (2009). O mundo rural como um espaço de vida: reflexões sobre a propriedade da terra, agricultura familiar e ruralidade. Porto Alegre: UFRGS.

Williams, R. (2011). O campo e a cidade na história e na literatura [1973] (Tradução de Paulo Henriques Britto). São Paulo: Companhia das Letras. 